\title{
Unemployment and mental health in a community population from a border city in Mexico
}

\author{
Benito Zamorano González ${ }^{\mathrm{a}}$, Fabiola Peña Cárdenas ${ }^{\mathrm{a}, *}$, Cristián Pinto-Cortez ${ }^{\mathrm{b}}$, \\ Yolanda Velázquez Narváez ${ }^{a}$, José Ignacio Vargas Martínez a and Lucía Ruíz Ramos ${ }^{a}$ \\ ${ }^{a}$ Universidad Autónoma de Tamaulipas, Ciudad Victoria, Tamaulipas, Mexico \\ ${ }^{\mathrm{b}}$ Universidad de Tarapacá, Arica, Chile
}

Received 27 August 2019

Accepted 23 August 2020

\begin{abstract}
.
BACKGROUND: The constant changes in the global economy generate instability in the markets, favoring the closing of companies, dismissals of personnel, job losses. Unemployment has been associated with adverse psychological effects, serving as a predictor of poor mental health.

OBJECTIVE: The main goal was to analyze the relation between work status and mental health.

METHODS: A cross-sectional, quantitative study was carried out with a sample of community population, inhabitants of the urban area of a Mexican city. The sample consisted of 1351 participants, being 577 men (43\%) and 774 women (57\%) with an average age of $41.46(\mathrm{SD}=17.00)$. The participants were selected by a quota sampling, in 13 representative points of Matamoros' city urban area. Home surveys were applied; the Spanish version of the Symptom Checklist 90 (SCL-90) was used for mental health assessment.

RESULTS: The model explaining the relation between work status and mental health (GFI) was significant $(p<0.01)$. Unemployment was related to higher scores in all sub-scales of psychopathologies evaluated by the SCL-90, in comparison with the rest of work status categories.

CONCLUSIONS: The unemployed, followed by housewives, presented indicators of poorer mental health, while the retired and those in strikes or lockouts showed the best mental health indexes.
\end{abstract}

Keywords: Work status, Mexican, SCL-90, psychopathology, non-clinical, economical crisis, Latin America

\section{Introduction}

Mental health is a matter of importance for the public health sector; the proper functioning of an individual in different social areas require some mental stability [1-4]. Studies on the epidemiology of mental disorders have shown a strong link between

\footnotetext{
*Address for correspondence: Fabiola Peña Cárdenas PhD., Universidad Autónoma de Tamaulipas. Unidad Académica Multidisciplinaria Matamoros-UAT. Ave. del Maestro y Marte s/n. Col. Alianza. H. Matamoros, Tamaulipas, C.P. 87410, México. Tel.: +528688122716; E-mail: fcardenas@ docentes.uat.edu.mx.
}

social conditions and the psychological well-being of individuals; factors such as socioeconomic status, neighborhoods characteristics, violence exposure, members of racial or ethnic minorities, gender and rapid social change present a differential risk for a range of mental disorders [4-12].

Furthermore, the constant changes in the global economy generate instability in the markets, favoring the closing of companies, dismissals of personnel, job losses [13, 14]. Unemployment has been associated with adverse psychological effects, serving as a predictor of poor mental health and a reduction in well-being and life satisfaction $[10,15]$. 
Empirical research suggests a relatively unidirectional causal effect of unemployment on psychological stress. Results of longitudinal studies have found that there is a stress increase after unemployment and the subsequent decrease when the individual gets employed again [16]. It has also been shown to have an impact on subjective well-being, self-esteem, quality of life or stability perceived by the individual $[10,16,17]$. Studies with a more clinical approach have shown that there is a relationship between the presence of different psychological disorders such as depression, anxiety or stress and unemployment [18-20].

Associated sociocultural factors and differentials such as sex or the reason for unemployment have also been analyzed; in the Greek population, for example, the adverse effect was more significant on women than on men; as well as in those cases in which unemployment was involuntary [21]. In Spain, similar results to those of Drydakis were evaluated but considering the status of the participant within the home as well, the impact of unemployment on mental health being higher in those lower-class males or workers who are the providers of the household, while in women, the greatest impact was found in those who do not perform manual labor and are associated with marital status as widows, separated or divorced, and who have to do household chores themselves [22, 23]. What is clear, as stated by Gili et al. [22], is that mental health is negatively affected during periods of economic distress.

Studies of the impact of unemployment and sociodemographic factors related to mental health are necessary due to the social and economic costs they represent. Large-scale epidemiological and longitudinal studies have shown the long-term effects not only of unemployment but also of early and temporary job losses due to sit-ins, strikes or company closures; demonstrating a correlation between these and the subsequent risks of labor instability, subsequent unemployment, as well as long-term health effects $[4,24,25]$. There have also been remarkably similar results produced by the individual dismissals as from company closures, as well as extended effects of unemployment in the communities [20,26], with which the existence of adverse mental health conditions that influence the loss of employment can be doubtful [27].

There is enough existing evidence about the effects of unemployment and sociocultural factors on the physical and mental health of individuals; In recent decades a large number of studies have been carried in
European countries to try to analyze the effects of the economic crises that have developed in recent years [28-33]. In the case of Latin America raises a somewhat different situation and that is that although there are economic crises, most of the countries are developing despite having more precarious economies and labor situations [34]. It could be considered that the effects of adverse social and employment situations tend to be maintained for extended and indefinite periods, thus the plunder on the quality of life, physical and mental health of the inhabitants [35]; this may differ for countries with more robust economies [36-39].

The study of the employment situation and its effects on mental health is at this moment crucial, especially in developing countries, in low income groups, or those with job insecurity [33], who are in more risk of stress and mental health problems, and facing the global economical crisis produced by the COVID-19 pandemic [40].

The present study has as main goal to analyze the relationship between the labor situation and the mental health of a sample of nonclinical and community population of the urban area of Matamoros, Tamaulipas, Mexico. Additionally, specific objectives are to analyze the relationship between mental health and other sociodemographic variables that are typically associated with mental health: marital status, educational level, and gender of the participants.

\section{Methods}

The study utilized a transversal, correlational and quantitative design. The population under study are adult inhabitants living in the urban area of the city of H. Matamoros, Tamaulipas, in Mexico. The sample consisted of a total of 1351 participants of both sexes, being 577 men (43\%) and 774 women (57\%) with an average age of $41.46(\mathrm{SD}=17.00)$. Participants were selected by non-probabilistic sampling by conglomerates by quotas. For this purpose, 13 representative points of the urban area of Matamoros city were selected to conduct home surveys. 105 surveys were applied by area, in the morning hours, in the afternoon and on the weekends, for safety reasons night shift was not considered to avoid interfering with the customs and sleep habits of the population. The criteria to include an individual was that the person lived in the domicile in which the visit was made and that them were adults, (18 years and older). Written consent was 
given before initiating the survey on mental health and employment status. The participation was anonymous and voluntary. Surveys were conducted using Survey Monkey application thru tablet-type devices with an Internet connection. Previous to data collection, the Institutional Research and Ethic Bureau of the Autonomous University of Tamaulipas, adscription of the principal's author, approved the research.

The sociodemographic data age, gender, educational level, marital status, and employment status were evaluated by closed-ended questions after obtaining consent. For the evaluation of mental health a Spanish version of the Symptom Checklist 90 (SCL-90) was used. The test in its original version was developed by Derogatis and Cleary [41] and it has been standardized for Mexico in its pencil and paper version [42] and adapted for computer use, showing very similar indexes [43]. The inventory has a total of 90 items that assess psychological distress, divided into nine dimensions for the diagnosis of psychological disorders. The test has been translated to multiple languages and has been used as a rapid screening test for the evaluation of the main diagnostic criteria of some psychological disorders, which can be used in multiple areas, including that of community research. The response options are Likert scale with scores of 1 to 4 points, considering $1=$ Never, $2=$ Almost never, 3 = Frequently, 4 = Very frequently. The measure dimensions are Somatization, Obsessions and Compulsions, Interpersonal Sensitivity, Depression, Anxiety, Hostility, Phobic Anxiety, Paranoid Ideation, and Psychoticism. The test can be answered in approximately 15 minutes, and the person is asked to respond based upon how they have felt in the last seven days.

Studies on its internal consistency in the Mexican population suggest that this is excellent with a Crombach's alpha $=0.96$ for the global scale; that is the measure of the GFI (Global Severity Index); while for separate scales these ranges between acceptable and good $(\omega=0.6-0.85)$, [42]. Additionally, in the present study their composite reliability was evaluated, by means of Omega coefficient for each of the subscales, being for Somatizations $(\omega=0.80)$, Obsessions and compulsions $(\omega=0.75)$, Interpersonal sensitivity $(\omega=0.75)$, Depression $(\omega=0.75)$, Anxiety $(\omega=0.70)$, Hostility $(\omega=0.72)$ and Psychoticism $(\omega=0.73)$, considered as good; whereas for Phobic Anxiety $(\omega=0.68)$, Paranoid Ideation $(\omega=0.63)$ these are acceptable. For the reasons as mentioned earlier, it is considered that the instrument has a good internal consistency for this study.
A pilot test was conducted prior to the study with 30 adult participants, which served as training for the interviewers and to make adjustments in informed consent before the final data collection. It should be mentioned that the data from the pilot test were not included in the study.

For analysis purposes, the data was prepared, and all records with missing or incomplete data were discarded, no data input was made. The statistical analyses were carried out using the statistical package SPSS version 24

\section{Results}

For the results analysis, linear regressions were performed in order to determine differences in the averages of each of the categories of the variables analyzed, using the GFI (global severity index) values as an indicator of mental health; Higher scores indicate a greater likelihood of psychopathology or severity, while lower scores point to better mental health. In order to observe the relationship between mental health and the various independent variables, a regression was carried out for each independent variable. The independent variables analyzed were: the work status (with the categories: not working, working, work stoppage or strike, retired, housewife and student); marital status (categorized into: single, married, widowed and divorced); the educational level (categorized in without studies, primary, secondary, preparatory, university and postgraduate); finally, sex (categorized into: male and female).

As shown in Table 1, a significant relation was found for the labor situation or productive activity model (Model 1, $p<0.01$ ), as well as for the marital status model (Model 2; $p<0.01$ ), and for gender (Model 4; $p<0.01$ ), whereas the educational level was not considered as significant (Model 3; $p$ values higher than 0.05 in all categories of the educational level).

To fulfill the general objective: To analyze the relation between work status and mental health, a model using the GFI score as a dependent variable was applied, with six predictor categories, of which the category determined as the basis for the regression was "no work ", while the rest of the categories were indicated as dummy variables. The model as a whole presents a significant adjustment. As can be seen in Table 1, the category "do not work" is associated with higher GFI scores than the rest of the categories $(\beta=0.400 ; p<0.001)$; serving as an indicator 
Table 1

Linear regression models for the prediction of the global severity index (GFI) by labor situation, marital status, educational level, and gender

\begin{tabular}{|c|c|c|c|c|c|}
\hline & \multicolumn{2}{|c|}{$\begin{array}{c}\text { Non-standardized } \\
\text { coefficients }\end{array}$} & \multirow{2}{*}{$\begin{array}{c}\begin{array}{c}\text { Standardized } \\
\text { coefficients }\end{array} \\
\text { Beta }\end{array}$} & \multirow[b]{2}{*}{$\mathrm{t}$} & \multirow[b]{2}{*}{ Sig. } \\
\hline & Beta & standard Error & & & \\
\hline \multicolumn{6}{|l|}{ Model 1: Work situation } \\
\hline a) Constant: Base Does not work & 0.400 & 0.030 & & 13.321 & $<0.001^{* *}$ \\
\hline b) Predictor: Works & -0.153 & 0.032 & -0.265 & -4.804 & $<0.001^{* *}$ \\
\hline c) Laboral stoppage & -0.292 & 0.120 & -0.068 & -2.435 & $0.015^{*}$ \\
\hline d) Retired & -0.158 & 0.046 & -0.121 & -3.475 & $0.001^{* *}$ \\
\hline e) Housewife & -0.089 & 0.034 & -0.132 & -2.622 & $0.009^{*}$ \\
\hline f) Student & -0.150 & 0.039 & -0.155 & -3.853 & $<0.001^{* *}$ \\
\hline \multicolumn{6}{|l|}{ Model 2: Marital status } \\
\hline a) Constant: Single Base & 0.313 & 0.014 & & 22.542 & $<0.001^{* *}$ \\
\hline b) Predictor: Married & -0.062 & 0.017 & -0.107 & -3.592 & $<0.001^{* *}$ \\
\hline c) Widowed & -0.050 & 0.033 & -0.044 & -1.520 & 0.129 \\
\hline d) Divorced & -0.049 & 0.037 & -0.038 & -1.326 & 0.185 \\
\hline \multicolumn{6}{|l|}{ Model 3: Educational level } \\
\hline a) Constant: Base Without studies & 0.267 & 0.038 & & 7.110 & $<0.001^{* *}$ \\
\hline b) Predictors: Primary & 0.032 & 0.042 & 0.041 & 0.757 & 0.449 \\
\hline c) Secondary & 0.051 & 0.041 & 0.074 & 1.242 & 0.214 \\
\hline d) High school & -0.003 & 0.040 & -0.004 & -0.067 & 0.947 \\
\hline e) University & -0.039 & 0.040 & -0.060 & -0.961 & 0.337 \\
\hline f) Postgraduate & -0.068 & 0.091 & -0.022 & -0.749 & 0.454 \\
\hline \multicolumn{6}{|l|}{ Model 4: Gender } \\
\hline a) Constant: Male Base & 0.234 & 0.012 & & 19.614 & $<0.001^{* *}$ \\
\hline b) Predictor: Female & 0.066 & 0.016 & 0.113 & 4.181 & $<0.001^{* *}$ \\
\hline
\end{tabular}

Note: ${ }^{*} p<0.05 ;{ }^{* *} p<0.01$.

of worse mental health compared to those with other productive activities. They are followed by the "housewives" $(\beta=-0.089, p=0.009)$, then the "students" $(\beta=-0.150 ; p<0.001)$; and those who "work" $(\beta=-0.153 ; p<0.001)$. While the lowest scores in this category, that is, better mental health are observed associated with the subjects of the categories "laboral stoppage" $(\beta=-0.292, p=0.015)$ and the "retired" $(\beta=-0.158 ; p<0.001)$.

Regarding the specific objective [1] of analyzing the association between marital status and the mental health of the participants; it was taken as the base category for the model, the status "single" $(\beta=0.313 ; p<0.001)$. The results show significant differences between this category the subjects from the group "married", but not with those of widow(er) or divorced; it is noteworthy that belonging to the group of "married" decreases the global severity index $(\beta=-0.062 ; p<0.001)$ regarding the group "single" (See Table 1).

For the specific objective [2], examining the association between the educational level and the mental health of the participants, model 3 tested the effect of this independent variable on the GFI, for which reference was made to the subjects "without studies", while for the rest of the categories they formed dummy variables. As can be seen, no significant differences were found between the base category and the rest of the categories, so it can be stated that the level of mental health is not influenced by the educational level for the study population (See Table 1).

Concerning the specific objective [3]; analyzing the relationship between mental health and gender, the category used as a basis was that of "male." As can be seen, belonging to the "female" category is significantly associated with an increase in the GFI score ( $\beta=0.066 ; p<0.001)$, being indicative of worse mental health regarding the "male" gender $(\beta=0.234$; $p<0.001$ ).

Once the impact of the sociodemographic variables on the global severity index has been determined; in order to fulfill the specific objective 4: Analyze the relationship between unemployment and psychopathologies evaluated by the SCL-90 a linear regression was performed for each one of the psychopathologies. Again, the category "does not work" was used as the base variable of the regression model, while average scores for each SCL-90 subscale were used as dependent variables; the results are presented in Table 2.

As can be seen, Model 1, referring to somatization, shows a good fit; revealing significant differences between the subjects that work and those who are students, to those that do not work. That is, unemployment is associated with higher somatization rates 
Table 2

Models of linear regressions for the prediction of psychological disorders on regards to the employment situation

\begin{tabular}{|c|c|c|c|c|c|}
\hline & \multicolumn{2}{|c|}{$\begin{array}{l}\text { Non-standardized } \\
\text { coefficients }\end{array}$} & \multirow{2}{*}{ 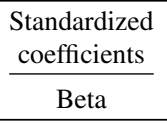 } & \multirow[b]{2}{*}{$\mathrm{t}$} & \multirow[b]{2}{*}{ Sig. } \\
\hline & Beta & Error standard & & & \\
\hline \multicolumn{6}{|l|}{ Model 1: Somatization } \\
\hline a) Constant: Base Does not work & 0.469 & 0.043 & & 10.878 & $<0.001^{* *}$ \\
\hline b) Predictor: Work & -0.155 & 0.046 & -0.186 & -3.382 & $0.001^{* *}$ \\
\hline c) Laboral stoppage & -0.289 & 0.173 & -0.046 & -1.674 & 0.094 \\
\hline d) Retired & -0.085 & 0.066 & -0.045 & -1.303 & 0.193 \\
\hline e) Housewife & -0.032 & 0.049 & -0.033 & -0.663 & 0.507 \\
\hline f) Student & -0.210 & 0.056 & -0.151 & -3.759 & $<0.001^{* *}$ \\
\hline \multicolumn{6}{|l|}{$\begin{array}{l}\text { Model 2: Obsessions } \\
\text { and compulsions }\end{array}$} \\
\hline a) Constant: Base does not work & 0.494 & 0.046 & & 10.837 & $<0.001^{* *}$ \\
\hline b) Predictor: Work & -0.142 & 0.048 & -0.162 & -2.928 & $0.003^{* *}$ \\
\hline c) Laboral stoppage & -0.311 & 0.183 & -0.048 & -1.705 & 0.088 \\
\hline d) Retired & -0.203 & 0.069 & -0.103 & -2.933 & $0.003^{* *}$ \\
\hline e) Housewife & -0.086 & 0.052 & -0.084 & -1.658 & 0.098 \\
\hline f) Student & -0.098 & 0.059 & -0.067 & -1.662 & 0.097 \\
\hline \multicolumn{6}{|l|}{ Model 3: Interpersonal sensitivity } \\
\hline a) Constant: Base Does not work & 0.391 & 0.040 & & 9.709 & $<0.001^{* *}$ \\
\hline b) Predictor: Work & -0.179 & 0.043 & -0.231 & -4.184 & $<0.001^{* *}$ \\
\hline c) Laboral stoppage & -0.280 & 0.161 & -0.048 & -1.738 & 0.082 \\
\hline d) Retired & -0.245 & 0.061 & -0.140 & -4.001 & $<0.001^{* *}$ \\
\hline e) Housewife & -0.118 & 0.046 & -0.130 & -2.576 & $0.010^{* *}$ \\
\hline f) Student & -0.152 & 0.052 & -0.118 & -2.920 & $0.004^{* *}$ \\
\hline \multicolumn{6}{|l|}{ Model 4: Depression } \\
\hline a) Constant: Base does not work & 0.443 & 0.037 & & 12.049 & $<0.001^{* *}$ \\
\hline b) Predictor: Work & -0.168 & 0.039 & -0.237 & -4.324 & $<0.001^{* *}$ \\
\hline c) Laboral stoppage & -0.417 & 0.147 & -0.078 & -2.838 & $0.005^{* *}$ \\
\hline d) Retired & -0.151 & 0.056 & -0.094 & -2.701 & $0.007^{* *}$ \\
\hline e) Housewife & -0.061 & 0.042 & -0.073 & -1.455 & 0.146 \\
\hline f) Student & -0.219 & 0.048 & -0.184 & -4.601 & $<0.001^{* *}$ \\
\hline \multicolumn{6}{|l|}{ Model 5: Anxiety } \\
\hline a) Constant: Base does not work & 0.290 & 0.033 & & 8.923 & $<0.001^{* *}$ \\
\hline b) Predictor: Work & -0.109 & 0.034 & -0.175 & -3.153 & $0.002^{* *}$ \\
\hline c) Laboral stoppage & -0.207 & 0.130 & -0.044 & -1.590 & 0.112 \\
\hline d) Retired & -0.099 & 0.049 & -0.070 & -2.000 & $0.046^{*}$ \\
\hline e) Housewife & -0.048 & 0.037 & -0.066 & -1.313 & 0.190 \\
\hline f) Student & -0.108 & 0.042 & -0.104 & -2.567 & $0.010^{* *}$ \\
\hline \multicolumn{6}{|l|}{ Model 6: Hostility } \\
\hline a) Constant: Base does not work & 0.372 & 0.043 & & 8.683 & $<0.001^{* *}$ \\
\hline b) Predictor: Work & -0.108 & 0.045 & -0.132 & -2.380 & $0.017^{*}$ \\
\hline c) Laboral stoppage & -0.372 & 0.171 & -0.061 & -2.171 & $0.030^{*}$ \\
\hline d) Retired & -0.126 & 0.065 & -0.068 & -1.934 & 0.053 \\
\hline e) Housewife & -0.142 & 0.049 & -0.148 & -2.932 & $0.003^{* *}$ \\
\hline f) Student & -0.061 & 0.056 & -0.045 & -1.107 & 0.268 \\
\hline \multicolumn{6}{|l|}{ Model 7: Phobic anxiety } \\
\hline a) Constant: Base Does not work & 0.252 & 0.040 & & 6.323 & $<0.001^{* *}$ \\
\hline b) Predictor: Work & -0.092 & 0.042 & -0.120 & -2.180 & $0.029^{*}$ \\
\hline c) Laboral stoppage & -0.085 & 0.159 & -0.015 & -0.535 & 0.593 \\
\hline d) Retired & -0.114 & 0.060 & -0.066 & -1.888 & 0.059 \\
\hline e) Housewife & 0.030 & 0.045 & 0.033 & 0.660 & 0.510 \\
\hline f) Student & -0.088 & 0.052 & -0.069 & -1.700 & 0.089 \\
\hline \multicolumn{6}{|l|}{ Model 8: Paranoid Ideation } \\
\hline a) Constant: Base does not work & 0.407 & 0.045 & & 9.071 & $<0.001^{* *}$ \\
\hline b) Predictor: Work & -0.121 & 0.048 & -0.142 & -2.551 & $0.011^{*}$ \\
\hline c) Laboral stoppage & -0.213 & 0.180 & -0.033 & -1.185 & 0.236 \\
\hline d) Retired & -0.202 & 0.068 & -0.104 & -2.964 & $0.003^{* *}$ \\
\hline e) Housewife & -0.128 & 0.051 & -0.128 & -2.525 & $0.012^{*}$ \\
\hline f) Student & -0.137 & 0.058 & -0.096 & -2.351 & $0.019^{* *}$ \\
\hline
\end{tabular}


Table 2

(Continued)

\begin{tabular}{|c|c|c|c|c|c|}
\hline & \multicolumn{2}{|c|}{$\begin{array}{l}\text { Non-standardized } \\
\text { coefficients }\end{array}$} & \multirow{2}{*}{$\begin{array}{c}\begin{array}{c}\text { Standardized } \\
\text { coefficients }\end{array} \\
\text { Beta }\end{array}$} & \multirow[b]{2}{*}{$\mathrm{t}$} & \multirow[b]{2}{*}{ Sig. } \\
\hline & Beta & Error standard & & & \\
\hline \multicolumn{6}{|l|}{ Model 9: Psychoticism } \\
\hline $\begin{array}{l}\text { a) Constant: Base } \\
\text { does not work }\end{array}$ & 0.291 & 0.026 & & 11.196 & $<0.001^{* *}$ \\
\hline b) Predictor: Work & -0.185 & 0.028 & -0.368 & -6.713 & $<0.001^{* *}$ \\
\hline c) Laboral stoppage & -0.274 & 0.104 & -0.073 & -2.639 & $0.008^{* *}$ \\
\hline d) Retired & -0.164 & 0.039 & -0.144 & -4.144 & $<0.001^{* *}$ \\
\hline e) Housewife & -0.162 & 0.029 & -0.275 & -5.512 & $<0.001^{* *}$ \\
\hline f) Student & -0.190 & 0.034 & -0.226 & -5.632 & $<0.001^{* *}$ \\
\hline
\end{tabular}

Note: ${ }^{*} p<0.05 ;{ }^{* *} p<0.01$.

in the unemployed than in the subjects who work or study. Model 2 shows that unemployment is associated with higher rates of obsessions and compulsions than working subjects and retired people. It is also associated with higher rates of "interpersonal sensitivity" than with those who work, retirees, housewives or students (Model 3). In terms of depression (Model 4), significant differences were also found between the unemployed and all the subcategories except for the "housewives," associating in all cases the other categories with a decrease in the indicators of "depression." The same for anxiety (Model 5), where significant differences were also found between the unemployed and all subcategories except for subcategory housewives, and in individuals on work stoppage, with unemployment associated with the increase in anxiety scores. The hostility model 6 also shows significant differences between the base category and the one that "works," "laboral stoppage" and "housewives." In the phobic anxiety model (Model 7) only significant differences were found between the category "unemployed" and "working." In paranoid ideation, significant differences were also found among the unemployed concerning the other categories, except for on strike or stoppage individuals. Finally, in model 9 significant differences were found between unemployed individuals and the rest of the categories; being associated in unemployment with an increase in psychoticism scores.

As can be observed, all the models that prove the influence of the variable "work situation" on the different psychological disorders evaluated by the SCL-90 showed a good adjustment. Furthermore, in all cases of significant differences between the category of "not working" or unemployed, belonging to any of the other categories (other than "not working") is associated with a decrease in the indicators of psychopathology (See Table 2).

\section{Discussion}

Regarding the main goal: Analyzing the relationship between the work situation and mental health, the results suggest that the work status has an impact on the overall mental health of the individual; specifically, significant differences were found among those individuals who "do not work" and the rest of the categories. This confirms what is stated by a significant number of studies that point out the impact of the employment situation on the mental health and subjective well-being of the individual [26, 33, 44-46]. Specifically, performing a job seems to have a significant positive impact on the overall mental health of the individual, in contrast to those unemployed individuals who show adverse effects. These results seem to support what was said in the study by Rodríguez et al. [47] who, in a sample of the Spanish population, found greater psychic morbidity among unstable and unemployed subjects compared to subjects with stable or regular jobs. They also support what is affirmed in the meta-analysis of Paul and Moser [15], in the sense that the effect of unemployment on mental health is associated with a higher rate of indicators of mixed psychopathologies such as stress, depression, anxiety, psychosomatic symptoms and self-esteem in unemployed subjects in contrast to subjects with secure or formal employment.

However, regarding the temporarily unemployed participants, contrary to what was stated by Paul and Moser [15], the results of the present study indicate that people in work stoppage have the lowest global severity indexes. Although the reason for this cannot be confirmed, due to the few participants that were found in this situation (only six subjects), that although they could be discarded from the analyzes, because these differences were not consistent in all the later psychopathologies, the authors decided that 
the most pertinent thing was to leave them in the analysis and take the interpretations regarding this category with the relevant reservations.

However, it is important to mention that in Mexico and specifically in the time and region in which the study was conducted, there were no frequent labor problems for strikes or union conflicts that presented a substantial danger of loss of employment for the worker. Analyzing the contextual reality in which the present study was carried out, it has been detected that the local companies faced with a risk or decrease in the demand for the products or services, instead of opting for mass layoffs, decide to keep them with a decrease in working days or provisionally closing production. The worker could consider this situation as a kind of "vacation" with or without pay, which far from generating stress would be considered a reinforcing stimulus. However, these are only some explanations, arguments and plausible reasoning that "a posteriori" of the results, the authors believe could explain this unexpected finding. Regarding the duration for example; some studies have found a positive correlation between the duration of unemployment and disorders such as depression and anxiety [20,48]. It would be important to corroborate these assumptions, through future studies in which all those factors are analyzed in depth: for example, the circumstances of unemployment, if the participant is in favor or against it, reasons, duration, among others.

Concerning specific objective 1: To analyze the relationship between marital status and mental health, it is observed that the predictive capacity of the civil status regarding the mental health of the participants is partial. Only one positive impact was found of the marital status married compared to the single category. This supports the findings of other studies in which married status seems to have a positive effect on mental health and increase subjective well-being indexes [44]. The divorced and widowed categories do not show significant differences in the GFI indexes regarding the single category.

The results seem to partially support the findings by Arias-de la Torre et al. [23], who found that the impact of unemployment on mental health is higher in those lower-class males or workers who are the providers of the household. While in women the most significant impact was found in those who do not perform manual labor and are associated with marital status as widows, separated or divorced, and who have to fulfill domestic chores themselves [23].

Regarding specific objective 2: Analyze the relationship between educational level and mental health:
The results of the present study did not find a significant correlation between educational level and the Global Severity Index, so it has not been considered as a determining predictive factor for mental health.

However, other moderating factors could be considered; for example, in the review study by Schaap et al. [49], when analyzing the relation between work output, early retirement at work and mental health, it is associated with more significant positive effects in those subjects with high socio-educational level than in those with a low socio-educational level.

Even more, concerning specific objective 3: Analyzing the relation between sex and mental health, as expected, the results of the study found a significant correlation between sex and the overall mental health of the participants. Women present higher global severity index scores regarding male participants.

The results partially concur with the study of Drydakis [21], carried out in Greece, in which, when assessing the impact on mental health of unemployment in terms of genders, a higher adverse effect was found on women than on men, as well as in those cases in which unemployment was involuntary [21].

In the matter of specific objective 4: Analyzing the relationship between unemployment and the symptoms of specific psychopathologies, as previously presented, all the models that prove the influence of the variable "work situation" on the different psychological disorders evaluated by the SCL-90 showed a significant relationship. Also, in all cases of significant differences between the category of "not working" or unemployed, belonging to any of the other categories is associated with a decrease with the indicators of psychopathology (See Table 2).

The results of the present study are consistent with those found in studies conducted worldwide. As previously mentioned, the meta-analysis of Paul and Moser [15], states that the effect of unemployment on mental health is associated with a higher rate of indicators of mixed psychopathologies such as stress, depression, anxiety, psychosomatic symptoms and self-esteem in unemployed subjects in contrast to the subjects with secure or formal employment.

The relation between depression and work situation in our study, found that indicators of depression are lower in subjects who are on strike or labral stoppage, followed by students and those who work. On the other hand, the highest scores in depression were found in those who do not work, followed by housewives and retirees. These results are consistent with those of the Goldman-Mellor study [50] and that of França et al. [51] where, there was an association 
between work inactivity and unemployment with the presence of mental disorders, specifically mood disorders such as depression, bipolar disorder and dysthymia in men; while in women the association was found only with respect to women inactive at work. Moreover, the indicators of paranoid ideation and higher psychoticism in this study associated with unemployment can be indicators of various disorders such as: schizophrenia or psychotic risk, as well as the use of illicit substances or drugs. This would also confirm what was found by Cotter et al. [52], which affirms that these are frequently associated with unemployment for prolonged periods of time.

Regarding interpersonal sensitivity, the results of this study are partially related to the results of Ogawa et al. [53]. The present study could confirm the results, in the sense that unemployment is associated with higher indicators of depression and interpersonal sensitivity, but also, in that these personal characteristics, as proposed by Ogawa et al. [53], become impediments for the person to look for a job and even more likely to be at home and be part of the study [54].

About the results of somatization and employment status, in the present investigation, higher scores were found regarding this indicator for the criteria "do not work" and lower scores for those with the criteria "work" and "students". These results concur with what was found in other studies [17,27], which have evidenced a higher frequency of psychosomatic symptoms and decrease in psychological well-being in unemployed individuals concerning employees.

\section{Conclusions}

In conclusion, it could be said that unemployment and lack of job stability represent a source of stress for modern societies, not only because of their economic repercussions but also because of their social and psychological consequences. The results of the present study showed a significant relation for the labor situation model $(p<0.01)$, in the same way for the civil status $(p<0.01)$, and $\operatorname{sex}(p<0.01)$, while the educational level was not considered significant to explain the general mental health index (GSI). When analyzing the relation between unemployment and the symptoms of specific psychopathologies, all the models that prove the influence of the variable "work situation" on the different psychological disorders evaluated by the SCL-90 showed a good adjustment. Also, in all cases of significant differences between the category of "not working" or unemployed, belonging to any of the other categories (other than "not working") is associated with a decrease with the indicators of psychopathology.

A large number of studies have shown that the loss of employment is associated with a significant increase in stress, depression, anxiety, and other psychosomatic symptoms. However, the loss of employment is not the only form of work inactivity. The present study has the advantage of analyzing a higher number of categories that seem to have peculiar characteristics different from that of the unemployed. In the current investigation these differentials have been found and analyzed considering people who simply do not do any work or do not have a formal job, in comparison with those who have jobs but who are in a situation of temporal unemployment or strike, or who do not perform a work activity because they are in retirement or in a retirement phase, finding that these categories have the lowest global severity indexes; therefore, better mental health.

Also, there was an evaluation on those who, although not working, perform an activity that is considered appropriate for their role within the family or society, such as students and housewives, finding significant differences between them and those who do not work. However, It is of special interest that after the unemployed, housewives have the highest global severity indexes, indicating a tendency to poor mental health.

Studies with a non-clinical population allow the evaluation of individuals with or without a specific pathology within their daily environment. In this type of studies, we seek to find possible relations between the display of different symptomatologies related to various mental disorders in subjects that are "a priori" considered healthy. This study presents the strength of being a study of this type, considering a nonclinical sample of inhabitants of the urban area of a city in Mexico. It has also used a scale that although initially has been built for clinical use, has also proven its effectiveness for rapid community screening and has also been developed and validated for the Mexican population in its computerized version, so it is presented as a good option to show valid data in the study population. However, it should always be remembered that these types of scales only have the purpose of warning about the presence of specific symptoms; in no way can be considered as a substitute for a clinical diagnosis that must be performed by a professional.

Although one cannot speak of causality due to the type of study, it is true that the results of the 
present research show the labor status, and specially the unemployment as a demographic factor with a significant relation with the general mental health of the individual.

Although the study was carried out prior to the COVID-19 pandemic, the authors consider that its practical implications and relevance will be increased in this period of economical crisis. The economic instability not only at the national but worldwide level, with company closings, layoffs, salary cuts, downsizing are causing a wave of changes in the employment situation of people. This possibly, in light of the results of the present study, will mean an increase in mental disorders in the general population. This study has practical implications for the public health system of the different countries, it requires actions in order to prevent and minimize the effects of the laboral crisis on the general mental health and assure the well-being of individuals. The results obtained on the psychopathologies presented in this study should be considered because it is a subclinical evaluation since symptom scales are used, which in general generate distress. However, severe disorders, by definition, are severely disabling.

The results of the study would also be of interest to employers, human resources department of different companies, corporations or small businesses, who must handle mental health issues of their workers. It is recommended to be attentive to possible behavioral and emotional changes of the employees for their respective referral to mental health services.

The authors of this research are conscious of its limitations, investigations of longitudinal type or that deepen in the causes, time of unemployment, as well as observing the impact in the social circles nearby and other related factors, are recommendable to reinforce the results of this study, as well as its replication in other geographical locations of the country to be able to generalize the results to other populations. More studies, carried out in developing countries, such as Mexico and Latin America, focusing on the effects of the economical crisis post-pandemic and mental health, seems necessary.

\section{Acknowledgments}

This manuscript was derived from a project with external funding by the Ministry of Public Education: DSA / 103.5 / 16712554 Urban noise and its effects on the health of the population. The project was carried out by the UAT-CA-99 Psychology and Risk Prevention, research group, from the Autonomous University of Tamaulipas and the PRECONRI Research Network (Prevention of Risk Behaviors).

\section{Conflict of interest}

\section{None to report.}

\section{References}

[1] Lashewicz B, Mitchell J, Boettcher N, Jones E, Wang J. You better be as stressed as I am: Working men's mental health amidst workplace expectations for busyness. Work. 2020;66(3):645-56.

[2] Cénat JM, Dalexis RD, Kokou-Kpolou CK, Mukunzi JN, Rousseau C. Social inequalities and collateral damages of the COVID-19 pandemic: when basic needs challenge mental health care. Int J Public Health. 2020;65(6):717-8.

[3] Vang C, Sun F, Sangalang CC. Mental health among the Hmong population in the U.S.: A systematic review of the influence of cultural and social factors. J Soc Work. 2020; $1-20$.

[4] Cohen A, Minas H. Mental health etiology: social determinants. In: Heggenhougen HK (Kris), editor. International encyclopedia of public health [Internet]. Oxford: Academic Press; 2008 [cited 2018 May 7]. pp. 350-3. Available from: https://www.sciencedirect.com/science/article/pii/B978012 3739605000411

[5] Brown B, Baker S. The social capitals of recovery in mental health. Health (N Y). 2020;24(4):384-402.

[6] Bamford J, Klabbers G, Curran E, Rosato M, Leavey G. Social Capital and Mental Health Among Black and Minority Ethnic Groups in the UK. J Immigr Minor Health [Internet]. Available from: https://link.springer.com/ article/10.1007/s10903-020-01043-0

[7] Lidwall U, Bill S, Palmer E, Olsson Bohlin C. Mental disorder sick leave in Sweden: A population study. Work. 2018;59(2):259-72.

[8] Oh H, Park SK. Gender and stress-buffering of social capital toward depression among precarious workers in South Korea. Work. 2020;66(1):53-62.

[9] Heser K, Kleineidam L, Pabst A, Wiese B, Roehr S, Löbner M, et al. Sex-Specific Associations Between Depressive Symptoms and Risk for Subsequent Dementia. J Alzheimers Dis. 2020;74(1):151-61.

[10] Ishmuhametov I, Palma A. Unemployment as a factor influencing mental well-being. Procedia Eng. 2017;178:359-67.

[11] Chabaud F, Benradia I, Bouet R, Caria A, Roelandt JL. Sociodemographic and mental health risk factors: Global and local conditions according to the Survey results 'mental health in the general population' in 18 international locations. Enceph-Rev Psychiatr Clin Biol Ther. 2017;43(6):540-57.

[12] Coduti WA, Anderson C, Lui K, Lui J, Rosenthal DA, Hursh N, et al. Psychologically healthy workplaces, disability management and employee mental health. J Vocat Rehabil. 2016;45(3):327-36. 
[13] Frasquilho D, Matos MG, Salonna F, Guerreiro D, Storti CC, Gaspar T, et al. Mental health outcomes in times of economic recession: a systematic literature review. BMC Public Health. 2016;16(1):115.

[14] Frasquilho D, de Matos MG, Marques A, Gaspar T, de Almeida JMC. Unemployment, life satisfaction and deprivation: Gender and partnership differences in the context of economic recession. Work. 2017;57(1):79-86.

[15] Paul KI, Moser K. Unemployment impairs mental health: Meta-analyses. J Vocat Behav. 2009;74(3):264-82.

[16] Bjarnason T, Sigurdardottir TJ. Psychological distress during unemployment and beyond: social support and material deprivation among youth in six northern European countries. Soc Sci Med. 2003;56(5):973-85.

[17] Aslund C, Starrin B, Nilsson KW. Psychosomatic symptoms and low psychological well-being in relation to employment status: the influence of social capital in a large crosssectional study in Sweden. Int J Equity Health. 2014;13:22.

[18] Alameda-Palacios J, Ruiz-Ramos M, García-Robredo B. Suicidio, prescripción de antidepresivos y desempleo en Andalucía. Gac Sanit. 2014;28(4):309-12.

[19] Medel-Herrero A, Gomez-Beneyto M. Impacto de la crisis económica del 2008 en el número de jóvenes hospitalizados por patología psiquiátrica. Rev Psiquiatr Salud Ment. 2019;12(1):28-36.

[20] Marrone J, Swarbrick MA. Long-Term Unemployment: A Social Determinant Underaddressed Within Community Behavioral Health Programs. Psychiatr Serv. 2020;71(7):745-8.

[21] Drydakis N. The effect of unemployment on self-reported health and mental health in Greece from 2008 to 2013: a longitudinal study before and during the financial crisis. Soc Sci Med 1982. 2015;128:43-51.

[22] Gili M, García Campayo J, Roca M. Crisis económica y salud mental. Informe SESPAS 2014. Gac Sanit. 2014;28:104-8.

[23] Arias-de la Torre J, Molina AJ, Fernández-Villa T, Artazcoz L, Martín V. Mental health, family roles and employment status inside and outside the household in Spain. Gac Sanit. 2019;33(3):235-41.

[24] Yu B, Chen X. Relationship Among Social Capital, Employment Uncertainty, Anxiety, and Suicidal Behaviors: A Chained Multi-mediator Mediation Modeling Analysis. Arch Suicide Res. 2020;0(0):1-19.

[25] Schauss E, Hawes K, Ellmo F, Brasfield MW. Surviving Job Loss Stress: Examining Dyadic Coping Process across Time. J Couple Relatsh Ther. 2020;1-17.

[26] Hart A, Psyllou A, Eryigit-Madzwamuse S, Heaver B, Rathbone A, Duncan S, et al. Transitions into work for young people with complex needs: a systematic review of UK and Ireland studies to improve employability. Br J Guid Couns. 2020;1-15.

[27] Brydsten A, Gustafsson PE, Hammarström A, San Sebastian M. Does contextual unemployment matter for health status across the life course? A longitudinal multilevel study exploring the link between neighbourhood unemployment and functional somatic symptoms. Health Place. 2017;43:113-20.

[28] Vecchio N, Mihala G, Sheridan J, Hilton MF, Whiteford H, Scuffham PA. A link between labor participation, mental health and class of medication for mental well-being. Econ Anal Policy. 2014;44(4):376-85.

[29] Harrison J, Dawson L. Occupational health: meeting the challenges of the next 20 years. Saf Health Work. 2016;7(2):143-9.
[30] Lucchini RG, London L. Global occupational health: current challenges and the need for urgent action. Ann Glob Health. 2014;80(4):251-6.

[31] Giorgi G, Arcangeli G, Mucci N, Cupelli V. Economic stress in the workplace: The impact of fear of the crisis on mental health. Work. 2015;51(1):135-42.

[32] De Fazio P, Cerminara G, Calabró G, Bruni A, Caroleo M, Altamura M, et al. Unemployment, perceived health status and coping: A study in Southern Italy. Work. 2016;53(1):219-24.

[33] Bert F, Gualano MR, Thomas R, Vergnano G, Voglino G, Siliquini R. Original Exploring the possible health consequences of job insecurity: a pilot study among young workers. Gac Sanit. 2020;34(4):385-92.

[34] Caraballo-Arias Y. Occupational safety and health in Venezuela. Ann Glob Health. 2015;81(4):512-21.

[35] González-Baltazar R, Hidalgo-Santacruz G, León-Cortés SG, Contreras-Estrada MI, Aldrete-Rodríguez MG, Hidalgo-González BJ, et al. Quality of work life and mental health in primary care physicians. Procedia Manuf. 2015;3:4935-40.

[36] LaDou J. International occupational health. Int J Hyg Environ Health. 2003;206(4):303-13.

[37] Lopez Steinmetz LC, Lopez Steinmetz RL, Carlos Godoy J. Is unemployment less important than expected for suicide attempted in developing regions? Occupational profile of suicide attempts in Jujuy, north westernmost Argentina. Int J Soc Psychiatry. 2020;66(1):67-75.

[38] Hawkins C, Bwanika JM, Ibanda M. Socio-economic factors associated with mental health disorders in Fort Portal, western Uganda. South Afr J Psychiatry. 2020;26:1-8.

[39] $\mathrm{Ng} \mathrm{IYH,} \mathrm{Tan} \mathrm{JQ.} \mathrm{Economic} \mathrm{distress} \mathrm{and} \mathrm{health:} \mathrm{A}$ fixed effects analysis of low-income persons in Singapore. Int $\mathrm{J}$ Soc Welf [Internet]. Available from: https://onlinelibrary.wiley.com/doi/abs/10.1111/ijsw.12426

[40] Baker MG. Nonrelocatable Occupations at Increased Risk During Pandemics: United States, 2018. Am J Public Health. 2020;110(8):1126-32.

[41] Derogatis LR, Cleary PA. Confirmation of the dimensional structure of the scl-90: A study in construct validation. J Clin Psychol. 1977;33(4):981-9.

[42] Cruz Fuentes CS, López Bello L, Blas García C, González Macías L, Chávez Balderas RA. Datos sobre la validez y confiabilidad de la Symptom Check List 90 (SCL90) en una muestra de sujetos mexicanos. Salud Ment. 2005;28(1):7281.

[43] González-Santos L, Mercadillo RE, Graff A, Barrios FA. Versión computarizada para la aplicación del Listado de Síntomas 90 (SCL 90) y del Inventario de Temperamento y Carácter (ITC). Salud Ment. 2007;30(4):31-40.

[44] Moxham LJ, Fernandez R, Kim B, Lapkin S, ten HamBaloyi W, Al Mutair A. Employment as a predictor of mental health, psychological distress, anxiety and depression in Australian pre-registration nursing students. J Prof Nurs. 2018;34(6):502-6.

[45] Brydsten A, Gustafsson PE, Hammarström A, San Sebastian M. Does contextual unemployment matter for health status across the life course? A longitudinal multilevel study exploring the link between neighbourhood unemployment and functional somatic symptoms. Health Place. 2017;43:113-20.

[46] Fryer D, Stambe R. Unemployment and Mental Health. In: Wright JD, editor. International Encyclopedia of the Social \& Behavioral Sciences (Second Edition) [Internet]. Oxford: Elsevier; 2015 [cited 2020 Sep 2].pp. 733-7. Available from: 
http://www.sciencedirect.com/science/article/pii/B9780080 970868140462

[47] Garrido Rodríguez P, Castillo Herraiz I, Benavides FG, Ruiz Pérez I. Situación laboral y salud mental. Resultados de un estudio transversal. Gac Sanit. 1994;8(42):128-32.

[48] Mossakowski KN. The influence of past unemployment duration on symptoms of depression among young women and men in the United States. Am J Public Health. 2009;99(10):1826-32.

[49] Schaap R, de Wind A, Coenen P, Proper K, Boot C. The effects of exit from work on health across different socioeconomic groups: A systematic literature review. Soc Sci Med. 2018;198:36-45.

[50] Goldman-Mellor SJ. Unemployment and mental health. In: Encyclopedia of mental health [Internet]. Elsevier; 2016 [cited 2018 Apr 20]. pp. 350-5. Available from: http://linkinghub.elsevier.com/retrieve/pii/B97801239704 59000537

[51] Henriques França M, Barreto Sandhi M, Garcia Pereira F, Guerra deAndrade LHS, Alochio dePaiva MC, Viana MC. Mental disorders and employment status in the São
Paulo Metropolitan Area, Brazil: gender differences and use of health services. Cad Saúde Pública [Internet]. 2017 [cited 2020 Sep 2];33(9). Available from: http:// www.scielo.br/scielo.php?script=sci_abstract\&pid=S0102$311 X 2017000905014 \& \operatorname{lng}=e n \& n r m=i s o \& t \operatorname{lng}=e n$

[52] Cotter J, Lin A, Drake RJ, Thompson A, Nelson B, McGorry $\mathrm{P}$, et al. Long-term employment among people at ultra-high risk for psychosis. Schizophr Res. 2017;184:26-31.

[53] Ogawa T, Shigemura J, Yoshino A, Nomura S. Interpersonal sensitivity associated with return to work status following sick leave: A cross-sectional study among Japanese workers with major depressive disorder. Asian J Psychiatry. 2013;6(2):146-50.

[54] Nieto-Flores MP, Berrios-Martos MP, Extremera N. Recursos personales asociados a diferentes indicadores de éxito en la búsqueda activa de empleo: Una revisión sistemática. Behav Psychol Conduct. 2015;23(2):373-92. 